\title{
Erratum to: Health-exploring complexity: an interdisciplinary systems approach HEC2016
}

\section{August-2 September 2016, Munich, Germany}

Eva Grill ${ }^{1}$ Martin Müller ${ }^{1}$ - Ulrich Mansmannn ${ }^{1}$

Published online: 28 November 2016

(C) Springer Science+Business Media Dordrecht 2016

\section{Erratum to: Eur J Epidemiol (2016) 31:S1-S239}

DOI 10.1007/s10654-016-0183-1

Unfortunately, a co-author name was missed in the abstract 264 published in Supplement 1, 2016. The correct author list is provided in this Erratum.

\section{4}

iCare-supporting people with increased need for care with smart and mobile IT

Bächle $\mathrm{M}^{1}$, Daurer $\mathrm{S}^{1}$, Judt $\mathrm{A}^{2}$, Mettler $\mathrm{T}^{3}$

${ }^{1}$ Baden-Wuerttemberg Cooperative State University, Ravensburg, Germany; ${ }^{2}$ Baden-Wuerttemberg Cooperative State University, Friedrichshafen, Germany; ${ }^{3}$ Universität St. Gallen, St. Gallen, Switzerland

The online version of the original article can be found under doi:10.1007/s10654-016-0183-1.

Martin Müller

Martin.Mueller@fh-rosenheim.de

1 Munich, Germany 